\title{
Reconsidering Patient Participation in Guideline Development
}

\author{
Hester M. van de Bovenkamp • \\ Margo J. Trappenburg
}

Published online: 20 December 2008

(C) The Author(s) 2008. This article is published with open access at Springerlink.com

\begin{abstract}
Health care has become increasingly patient-centred and medical guidelines are considered to be one of the instruments that contribute towards making it so. We reviewed the literature to identify studies on this subject. Both normative and empirical studies were analysed. Many studies recommend active patient participation in the process of guideline development as the instrument to make guidelines more patient-centred. This is done on the assumption that active patient participation will enhance the quality of the guidelines. We found no empirical evidence, however, to support this assumption. Moreover, the studies show that patients experience several difficulties in the participation process, which cannot solely be traced back to flawed practices. Given this poor track record we conclude that the plea to actively involve patients in the guideline development process should be reconsidered.
\end{abstract}

Keywords Patient participation - Medical guidelines - Patient-centred medicine

\section{Introduction}

Patient-centred medicine is one of the dominant paradigms if not the dominant paradigm in modern health care systems. It focuses on patient participation at different levels of decision-making. The paradigm is strongest in individual

\footnotetext{
H. M. van de Bovenkamp ( $\square)$

Institute of Health Policy and Management, Erasmus Medical Centre Rotterdam, iBMG J8-47, Postbus 1738, 3000 DR Rotterdam, The Netherlands

e-mail: h.vandebovenkamp@erasmusmc.nl
}

\section{J. Trappenburg}

Utrecht School of Governance, Utrecht, The Netherlands

e-mail: M.J.Trappenburg@uu.nl 
physician-patient contacts, in which ample attention is paid to the individual patient's point of view and to his or her needs and preferences [5]. It is assumed that patients and doctors engage in a process of shared decision-making. For example, patients must be given all the information they need in order to choose between treatment $\mathrm{A}$ and treatment B. Physicians should help patients in making these decisions. Arguments in favour of patient-centred medicine are mainly principle based since patient autonomy is considered a basic value, but they also have a practical side; patient-centred medicine is assumed to improve adherence to treatment recommendations [24]. According to Salmon and Hall [37, 38] the scientific basis for the importance of choice and control is weak. They argue that the discourse of patient empowerment became so strong partly because it offers clinicians a perfect way to withdraw from areas of patient need that are problematic for them, such as unexplained symptoms, chronic disease, and pain. Responsibility for these complicated forms of illness are gladly transferred to the empowered patient $[37,38]$. Still even these sceptical authors, who do not applaud the recent developments acknowledge that patient-centredness has become a dominant paradigm in modern medicine.

The individual physician-patient level is not the only level of decision-making in health care that is becoming more patient-centred. Increasingly, patient representatives, in the Netherlands often volunteers of patient organisations, are asked to participate in decision-making at the macro level. They can voice their opinion on the medical research agenda [9], evaluate health care laws and advise on national policy [47] and contribute to medical guideline development. In this paper we will focus on the latter. In the Netherlands, as in other countries, patient participation in guideline development is becoming increasingly common. It was encouraged by the Dutch government in 1995 [48]. In 2000, the Dutch Health Council, an important domestic advisory body, proposed patient participation in the development of guidelines [19]. Since then, organisations charged with guideline production in the Netherlands have been trying to actively involve patients in the guideline development process [50, 56, 57]. Earlier, this democratic approach had been adopted by countries such as Australia and the United Kingdom and it is also found in other countries [22, 35, 41, 51].

One of the items on the AGREE (Appraisal of Guideline Research and Evaluation) instrument, a European checklist to assess the quality of professional guidelines, stipulates that a high quality guideline should take patients' preferences into account [1]. But how should this be done? In this article we present a review of the literature search we performed on patient participation in guideline development with a view to answering the following question: What is the current state of the debate and the current state of affairs regarding patient participation in guideline development? After the Methods section, we first describe the studies we found and the arguments identified in the literature on this subject. Subsequently, we concentrate on the studies that report on patient participation in guideline development practice. In the Discussion we argue, on the basis of the literature, that increasing active patient participation in guideline development is not as logical a step towards patient-centred medicine as it may seem. 


\section{Methods}

To answer the research question we performed a literature search in Pubmed/ Medline, the Cochrane Library, Web of Science and the online contents on the subject of patient participation in guideline development. The keywords used were: patient participation guideline development (84 hits), consumer participation guideline development (117 hits), patient involvement guideline development (103 hits) and consumer involvement guideline development (121 hits). Out of a total of 425,86 hits seemed relevant to our research question on the basis of title and abstract (double hits excluded), but after closer inspection only 20 articles remained. Regrettably, we had to exclude studies and letters not written in either English or Dutch. We also excluded studies that did not refer to patient participation in guideline development in any way. We found additional publications by means of the chain referral technique, i.e., by also examining the lists of references of the studies selected. In addition, in the 'grey' literature including (commissioned) research, advisory and experiential reports, we found evaluations and other research reports on patient participation in guideline development. After close scrutiny of these publications, we selected 22 studies thus bringing the total to 42 .

The main, or very important focus, of 20 of the studies we selected was patient participation in guideline development. Three studies dealt with patient participation in decision-making processes in general, including guideline development. Seventeen articles dealt with guideline development processes in general, including patient participation. The last two publications were reflections on evidence-based practice and other popular concepts in health care in which guidelines, and patient participation in guideline development, was one of the subjects discussed. An overview of these articles is presented in Table 1. We performed a content analysis on these articles which resulted in a preliminary analytical scheme after six articles, which was refined after analyzing the other studies. The definitive analysis scheme consisted of the following subjects: (1) the nature of the study (empirical or not) (2) the focus of the article (was patient participation the main focus of the article), (3) the kind of guideline that was studied, (4) the arguments used for participation, (5) the participation methods, (6) the difficulties encountered, (7) the added value of participation and (8) the recommendations for the future.

\section{Results}

We categorised the studies into empirical studies that studied guideline development in practice, and non-empirical studies. Of the empirical studies, several authors specifically studied patient participation in guideline development. Van Wersch and Eccles [51] compared different participation methods in clinical practice by means of a number of case studies. Van Wersch and Van Den Akker [52] and Jarret and PIU [25] interviewed chairpersons and patient representatives, who had participated in guideline development groups, about their experiences. Lanza [27] reported on her experiences with patient participation in a focus group and survey research. Sieders [43], himself a patient representative in a development group, compiled his 
Table 1 Studies on patient participation in guideline development

\begin{tabular}{ll}
\hline Main or very important focus & Not main focus \\
\hline Nease and Owen (1994) [31] & Articles on patient participation in decision-making \\
Bastian (1996) [3] & Williamson (1998) [54] \\
Duff et al. (1996) [14] & Crawford et al. (2002) [12] \\
Butow et al. (1996) [8] & Nilsen et al. (2006) [32] \\
Schofield et al. (1997) [40] & Articles on guideline development in general \\
Owens (1998) [33] & Field et al. (1992) [16] \\
Bauchner et al. (1998) [4] & Gilmore (1993) [20] \\
Saltman (1998) [39] & Carter et al. (1995) [10] \\
Lanza et al. (2000) [27] & Grilli et al. (1996) [23] \\
Van Wersch and Eccles (2001) [51] & Eccles et al. (1996) [15] \\
Rankin et al. (2000) [35] & Smallwood and Lapsley (1996) [44] \\
Kelson (2001) [26] & McInnes et al. (2000) [29] \\
Rogers (2002) [36] & Gandjour et al. (2001) [17] \\
Cavelaars et al. (2002) [11] & Graham et al. (2003) [22] \\
Jarret et al. (2004) [25] & Pagliari and Grimshaw (2002) [34] \\
Van Veenendaal et al. (2004) [50] & Burgers et al. (2004) [7] \\
Goossensen et al. (2005) [21] & Brainin et al. (2004) [6] \\
Van Wersch and Van Den Akker (2005) [52] & Moreira et al. (2005) [30] \\
Schunemann et al. (2006) [41] & Smolders and Braspenning (2005) [45] \\
Sieders (2006) [43] & Lui et al. (2006) [28] \\
& Wright et al. (2006) [55] \\
& Schunemann et al. (2007) [42] \\
& Articles on popular concepts in health care \\
& Grol (2001) [24] \\
& Swinkels et al. (2002) [46] \\
\hline & \\
&
\end{tabular}

experiences in an extensive report consisting of, amongst others, e-mail messages and documents his patient organisation had developed as input for the process. The other empirical studies we found consisted of surveys amongst guideline developers that included a question on their ideas on, or their practice of patient participation [10, 22, 23]. Burgers et al. [7] analysed guidelines on oncology on quality criteria including patient participation. Smolders et al. [45] did the same for guidelines on depression. In addition, several authors did a survey on patient communication preferences and compared these to the (draft) guidelines [8, 35, 40]. Goossensen et al. [21] also conducted a survey on patient preferences, but in this case the information was used in the guideline development process. Gandjour et al. [17] studied a guideline development process. In this guideline attention was paid to the stages in which patient preferences might be considered. Others performed case studies of guideline development (groups) in which patient representatives participated [15, 28-30, 34, 42, 55]. 
It is very difficult if not impossible to study the effects of patient participation using Randomized Controlled Trials (RCTs). One cannot very well imagine a research set up of guideline development groups with and without patient representatives, engaging in the exact same quest. Decision-making processes must be studied in different ways, for example by doing case studies, surveys, interviews and guideline analysis. Thus, the studies we found cannot be dismissed as methodologically flawed, many of them provide us with insights in complicated processes.

The non-empirical articles, first of all, consisted of literature reviews [4, 11, 12, 24, 32, 33, 41, 46]. Secondly, we found articles reflecting recommendations of committees or guideline developers on how to best develop and implement guidelines $[6,16,26,44,50]$. Two articles reflected on seminars that had been organised to discuss guideline development $[14,20]$. Then there were articles that referred to some publications but that could best be categorised as statements of opinion [3, 36, 39, 49]. Finally, Nease and Owens [31] searched the literature and tested a model on the cost effectiveness of incorporating the preferences of individual patients into clinical practice guidelines. An overview of the nature of the studies is presented in Table 2 .

\section{Patients and Guidelines: The Ideas}

Our literature search showed that patient involvement in guidelines became a subject of interest from the early 1990s onwards. We identified two strands of thought in the literature:

1. Authors who argued that it is important for patients to participate actively in the guideline development process.

2. Authors who argued that guidelines should accommodate individual patient preferences without seeking active patient participation in the guideline development process.

We begin by discussing the focus on active participation of patients in guideline development. It is argued that participation is a consequence of the increasing importance of the consumer's choice in health care as we pointed out in the Introduction [3, 36]. The first strand of thought pleading strongly for active participation can be found in the articles by Bastian [3] and Duff et al. [14]. In 1996, Duff et al. [14] reported that patient participation in guideline development had indeed been put into practice from time to time, but not nearly enough. Both Bastian [3] and Duff et al. [14] argued that patients should be involved actively in the development process using different strategies such as co-opting consumer representatives into the guideline development group, a literature search into patient preferences, and community consultation. At this time other studies show that there is little support for this amongst doctors and guideline developers, however [10, 23]. Still, it is argued by Bastian and Duff et al. that a truly collaborative approach should be taken and that this would enable patients to climb Arnstein's ladder of participation. Arnstein [2] developed a ladder of citizen participation consisting of the rungs: manipulation, therapy (together 


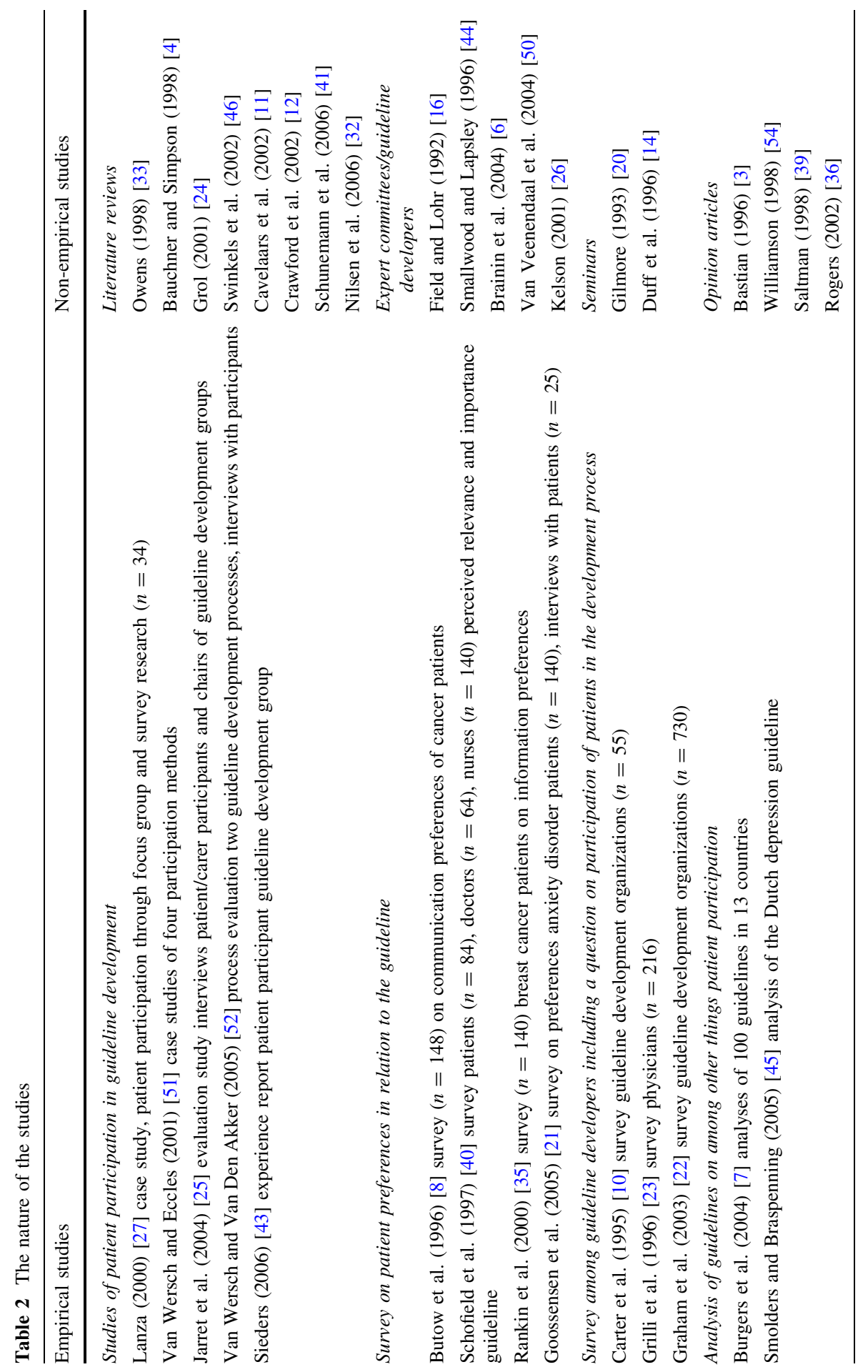




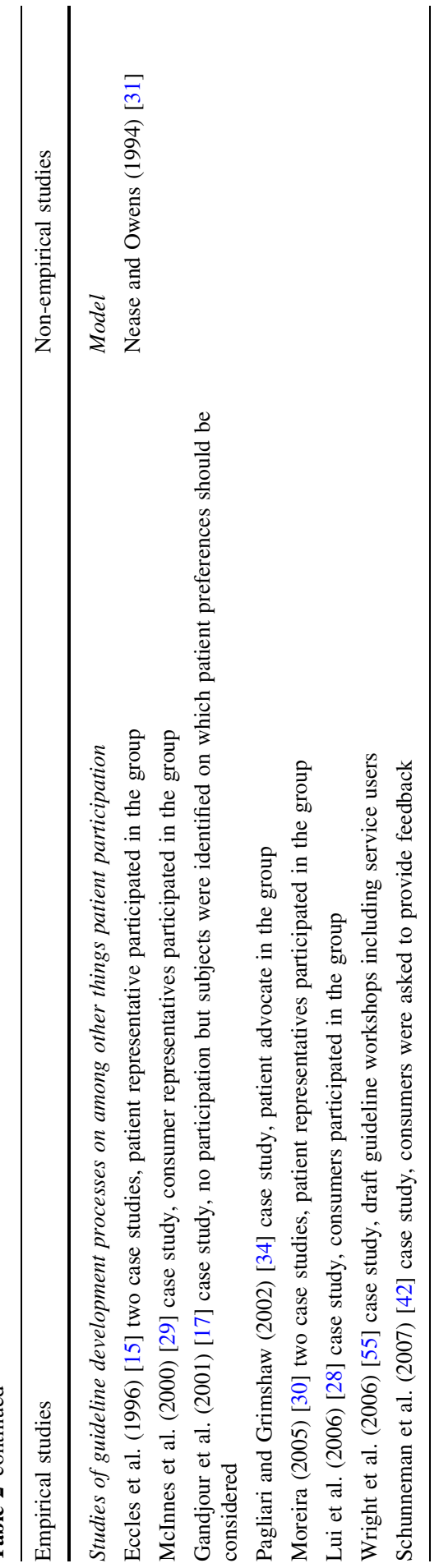


non-participation), informing, consultation, placation (together tokenism) and partnership, delegated power, citizen control (together citizen power). Over the years, similar versions of a ladder of participation have been developed including one for patient participation in guideline development [50]. Other authors followed the line of reasoning of Bastian and Duff using three sets of arguments for active patient participation: improved quality, increased legitimacy and principle based desirability (ideology). Nineteen provided arguments in favour of active patient participation; all of them arguing that this would lead to better decision-making, hence improved quality $[3,4,7,11,12,14,21,23,24,26,29,32,36,39$, 46, 4952]. Because of their experience with health care services, patients supposedly have additional knowledge over and above that of physicians and researchers. Hence, their participation may lead to better health care. Integrating patient preferences into the guidelines will make them more applicable to health care practice and, therefore, the chance of implementing the guidelines is increased.

The second set of arguments claims that patient participation increases the legitimacy of the guidelines, since all parties were involved and the process was more open [3, 11, 12, 23, 32, 50, 52]. The third line of argument is principle based $[3,11,12,21,32,36,50,52]$. Authors put forward that patient participation is important simply because it is the right thing to do. Patients are the ones affected most by these decision-making processes and, therefore, it seems only fair that they should have a say in the matter. Furthermore, patients' participation could contribute to their empowerment as well as induce social change and shift the balance of power between the actors in the health care sector. Also, participation is politically desirable because it encourages participative democracy.

In contrast to the first strand of thought we found in the literature, the second strand of thought emphasised the importance of devoting space to individual patient preferences in the guidelines without seeking active patient participation in the guideline development process. Owens [33] argued that since patients' views about the quality of life with specific states of health and consequently about their preferred therapy can vary greatly, guidelines should not be written as if patients were all the same. To increase the quality of the guidelines (their legitimacy, acceptability and usefulness), guidelines should include recommendations on topics on which patients' preferences vary, specifying how doctors can help patients to choose according to their preferences. Other authors supported this plea for devoting space in the guidelines to accommodate individual patient preferences [17, 20, 31]. Thus, guidelines can help make the individual patient-doctor contact more patientcentred, a paradigm that is, as we stated in the Introduction, very strong in modern health care [5, 37, 38].

The first strand of thought-active patient participation in the guideline development process-has become dominant in the discussion on patient-centred medicine with regard to guidelines (Table 3). Although a number of authors stressed the importance of both active patient participation in the development process and individual patient preferences, the latter argument has become rare in recent years. Even though authors differ on how intensively and in what way it should be achieved, most agree that patients should participate actively in the process. Since 
Table 3 Patients and guidelines

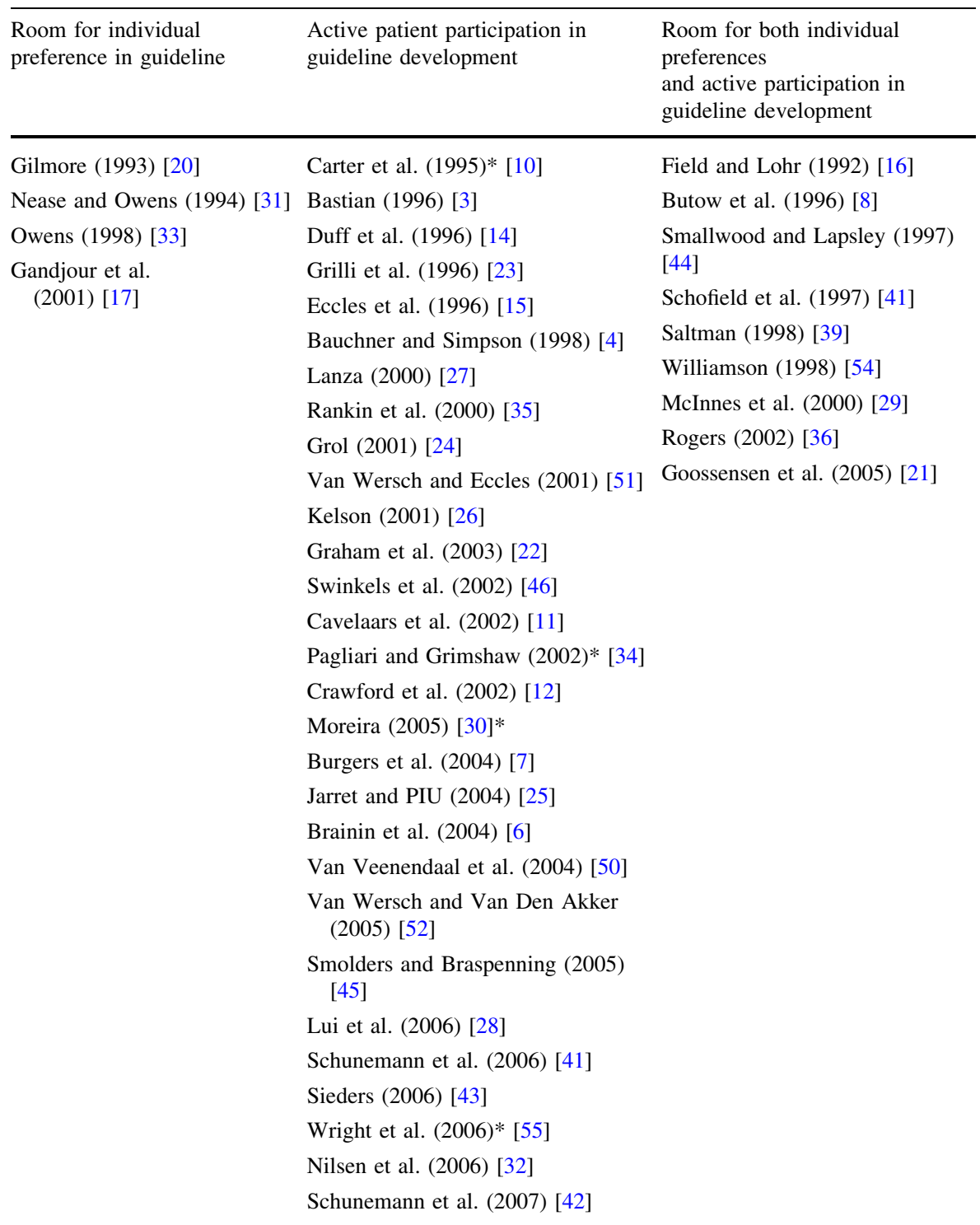

* These studies report on active patient participation but do not express views on its desirability

active participation in the guideline development process has become the dominant argument we concentrate on it in the following section.

Patient Participation in Guideline Development: Practice

Increasingly, patient participation is being put into practice. After a survey amongst developers of 730 Canadian guidelines that were published between 1994 and 1999, 
Graham et al. [22] concluded that in $19.6 \%$ of them patients and consumers were involved in the development committees. This number has increased steadily in these years; $51 \%$ of the guidelines drawn up in 1998-1999 were developed with patients participating in the committees.

The message conveyed by these articles and documents is that involving patients in guideline development is a good thing. We did not find any articles that opposed patient involvement, although apparently doctors and guideline development organisations did not always look forward to the idea [10,23]. The articles that did not specifically address the practice of participation did all advocate it, even though Nilsen et al. [32] concluded on the basis of a systematic review on patient participation in decision-making that there is a lack of research that reliably investigates whether consumer involvement actually delivers what it is supposed to (improved quality and legitimacy). Because of this lack of clear evidence authors simply stated that they believe patient participation is important. Alternatively, they referred to literature that showed that patients and health care professionals hold different opinions on certain subjects and thus concluded that both parties ought to have a say in guideline development. For instance, Bauchner and Simpson [4] referred to a study that showed that parents and health care professionals think differently on diagnostic testing and diagnostic error.

The lack of evidence for the claims made can be explained by the fact that patient participation in guideline development was not the main focus of all these studies. However, when reading the literature it also seems that the importance of patient involvement in guideline development was considered self-evident. For instance, Saltman [39] argued that clearly it is appropriate for consumers to be involved. That it is considered self-evident is also demonstrated by the fact that several authors stated as a matter of fact that patients had been involved in the guideline development processes researched by them [28, 30, 34, 42, 55]. Graham et al. [22] considered it a bad thing if patients had not been involved. This attitude can be interpreted as a sign that patient participation has become standard practice.

We now take a closer look at the studies that do report on experience with patient participation in practice. We concentrate on the participation methods that were used, the effects of participation and the difficulties encountered in the process.

The literature mentions several methods of patient participation. One such method is to carry out a survey into patient preferences on a certain subject at the time of guideline development [21, 27, 35]. Apparently, such surveys are often not feasible because of budgetary constraints [11]. Surveying patient preferences can, of course, also be part of the literature search of the guideline development group in the sense that the state of the art concerning patient preferences is distilled from the literature rather than organising a fact-finding mission oneself. Such a literature search is generally not considered a form of active patient participation in guideline development. Other methods of active participation mentioned in the literature are patient focus groups, in which insight can be gained on patient preferences which can be used as input in the guideline development process. Patient participation can also be put into practice by letting patient representatives give feedback on draft guidelines. Another method is enrolling patient representatives in the guideline development groups. The latter method is mentioned most in the literature. 
Van Wersch and Eccles [51] are the only authors who compared different methods of participation in practice. They studied the following methods:

(i) co-opting a patient into the guideline development group,

(ii) organising a one-time focus group,

(iii) holding a workshop where patients came together four times, and

(iv) co-opting a professional patient advocate into the development group.

The authors studied these four methods through a series of case studies within the North of England evidence-based guideline development program. The authors came to the conclusion that overall the individual patients in the guideline development groups have very little input. Patients contribute most on the subject of patient education, although subsequently their contributions are not acted upon. In the one-time focus group patients are most interested in patient education and selfmanagement. They also suggest ways of making guidelines better accessible to laypersons. The patients in the focus group have difficulties with the medical terminology and the authors questioned whether they understand scientific evidence on cost-efficiency. The workshop method is resource intensive. In order for them to understand the process patients are taught through role play how the guideline development procedure works. They also put forward some suggestions to make the guidelines better accessible to laypersons (changing colours, the use of strong/weak evidence instead of A, B, C, D, using brand names, etc.). The patient advocate in the group understands the terminology and can contribute to the process. However, she is not herself a patient. The authors concluded that consumers should be involved in all stages of guideline development by using several methods at once, and supporting patients throughout the process. Other studies arrived at similar conclusions. Authors usually observed a paucity of information on which methods work best and that it is, therefore, desirable to use different methods at once $[3,11$, $14,25,26,36,50,51]$. None of the studies concluded that this lack of evidence is a reason to stop patient participation.

Patients' experiences with participation vary. A study on the experiences of patient representatives in development groups and chairpersons of these groups in the British National Health Service (NHS) guideline development process, showed that most of them look back on a positive experience [25]. Accounts of patient representatives who do not evaluate their efforts as positive were also found [43, 52]. Sieders, a volunteer patient representative himself, advises other patients, who might consider participation in a guideline development group, against doing so [43].

\section{Participation in Guideline Development: Not an Easy Task}

Most authors argued in favour of patient participation in guideline development because, supposedly, it increases the quality of the guidelines. There is, however, little evidence in support of this supposition. Van Wersch and Eccles [51, p. 15] even concluded that: 'having involved consumers within the guideline development process (...) did not necessarily alter the content of the guidelines'. Schunemann et al. [42] concluded that the feedback of consumers on the WHO H5N1 virus 
guideline did not differ importantly from the panel, which consisted of clinical, methodological, basic science experts and country representatives, and there were no additional outcomes identified. Patients' contribution to the process is mostly on issues of communication and patient education [12, 21, 25, 26, 29, 51, 52]. What subsequently happens to their input and what it consists of exactly is not clear. After a patient survey on the need for psychosocial care for breast cancer patients one study concludes that the findings suggest that the draft guidelines adequately reflect consumer opinions [35]. The article is not clear about patient participation in the development of the draft guideline, so it is not possible to determine whether the guideline's fitting contents were the result of patient input at an earlier stage. This difficulty of assessing the contribution patients make to the decision-making process is not only seen in guideline development but in other decision-making processes as well [32]. It is interesting to note that in the descriptions of the participation process in guideline development groups, studies concentrated on the question whether patients are up to the task instead of concentrating on their contribution to the content of the process. The general conclusion was that patients can participate provided they are given proper support. For instance they should be trained to perform the task and chairpersons of the development groups should make sure that patients can deliver their input. The studies therefore conclude that certain adjustments in the participation process are warranted for participation $[11,25,26$, $51,52]$.

Nevertheless, several difficulties were identified that cut deeper. There is uncertainty amongst participants about the goals of participation [27, 36, 51, 52] and patients have difficulty following medical jargon and assessing technical medical literature $[11,25,26,36,41,51,52]$. Several authors pointed out that as a consequence the patients gave little input [15, 26, 30, 51, 52]. According to Eccles et al. [15, p. 48] patients in the development group were 'often non-participating observers of technical discussion to which they could offer no input'. The difficulties identified can lead to high selection standards for patient candidates. For instance, one of the qualifications on the job description for a prospective member in the guideline development group used by the National Institute for Health and Clinical Excellence (NICE), part of the NHS and responsible for the development of guidelines, is the ability to understand scientific articles [25]. If, however, only highly educated patient representatives are recruited, how representative is the patient input? Some studies acknowledged this problem [14, 21, 41]. For example, Goossensen et al. [21] argued that with a patient representative in the development group, the opinion of a small, articulate group is represented. Therefore, a survey of patient preferences is proposed in addition to this form of participation.

Another difficulty that is encountered is the integration of patients' experiential knowledge in an otherwise evidence-based guideline [25, 45, 51, 52]. Sometimes patients' input is not taken seriously because it is not based on scientific evidence. Van Wersch and Van Den Akker [52, p. 20] even concluded that patient representatives felt that 'experiential knowledge was not considered as knowledge at all'. This could well lead to disappointment amongst the patient representatives involved [43, 45, 52]. 
Such intensive participation processes involve considerable costs, an aspect that is almost completely ignored in the literature. The guideline development organisation has to invest a considerable amount of time and money. More importantly, the process also requires a substantial amount of time and effort from the patient representatives who participate in guideline development groups. A volunteer patient representative in the guideline development group on eating disorders in the Netherlands calculated that his efforts had cost him a total of $2,000 \mathrm{~h}$. He had tried to adhere to the evidence-based medicine (EBM) structure of the development process and had searched medical databases for publications. In other words, he had become a full member of the group. Still, he felt that his contribution was not taken seriously. The patient organisation he represented, therefore, did not endorse the guideline [43].

These problems encountered in the practice of patient participation in guideline development do not seem to be easily overcome by training or support of patients.

\section{The Future}

At the beginning of this debate it was argued that not much is known about the contribution of patients in practice or what methods should be used [4, 14]. Presently, 10 years later, these questions still remain unanswered [32]. After identifying the existing difficulties authors concluded that it is important to continue the participation process and that it should, therefore, be improved and intensified. Many authors argued that a combination of methods should be used, including active participation, throughout the development process. Most authors concluded that patient representatives should receive more guidance during the process. Patient participants ought to be trained, prepared and educated to fulfil their task $[11,25$, $26,51,52]$. Moreover, further research is recommended on how to make a success of the development process. Few if any authors argued for less intensive methods. Except for Sieders [43], who advised patients against participating in a development group, and Eccles et al. [15], who proposed, after having studied patients in action in guideline development groups, that this is not the correct way to include patient input. They argued for a focus group. Another study argued for a survey as a viable alternative [35]. However, Cavelaars et al. [11] concluded that doing a survey at the time of guideline development is very costly and not a plausible alternative for that reason.

We conclude that most authors do not recommend less intensive patient participation nor do they search for less active ways of incorporating patient preferences.

\section{Discussion}

Creating room to accommodate patient input in guidelines has been a subject of discussion since the 1990s. We identified two strands of thought in the early years of the debate. The first was to let patients actively participate in the process of guideline development through the use of focus groups and surveys, but especially by 
co-opting patient representatives into the development group. The second was to include recommendations in the guidelines that specify the importance of attention to individual patient preferences at the physician-patient level. The first strand of thought has become the dominant one in the debate. The most important argument in its favour is that patient participation would improve the quality of the guidelines. Other arguments are principle based or stressed the increased legitimacy of decisionmaking.

\section{Is Active Participation Patient-Centred?}

Although the general consensus seems to be that patients should be involved in guideline development, the added value of their participation has yet to be established. When participation is studied in practice the conclusion is usually that patients can participate provided they receive proper support. Apparently authors assume that patients can be trained to become full members in a guideline development group and therefore ought to be included. However, training and supporting patients to be able to participate as full members in an EBM guideline development process is a double edged sword; one can wonder whether this is the right way to go forward. Patients who have been trained and supported become fellow academics; they may no longer be able to contribute the experiential knowledge for which they were asked to participate in the first place. Patients who were not properly trained do contribute this experiential knowledge, but studies have shown that it is difficult to incorporate this in EBM guidelines.

When empirical evidence for something (a treatment, a management strategy, a decision-making process) is not found, two options may be considered. Firstly, it could be argued that more research should be done and conditions should be improved so as to make the proposed practice a success. Secondly, it could be argued that it is time to explore other alternatives. The existing literature on patient participation in guideline development proposes the first option. We feel it is important to broaden the debate and that is time to consider the second. In our view, the results in the literature show that active participation in guideline development is not the best way towards making health care more patient-centred.

We do not argue that patient preferences are not important. On the contrary, patients who want to be involved in decisions about their health and health care should be given the opportunity to do so, and guidelines can help to make this possible. The other line of reasoning, room for individual patient preferences in the guidelines, which has largely disappeared from the debate, could be reconsidered to accomplish this. This should not be considered as a step backwards in patientcentred medicine but rather as a way to best accomplishing it. Apart from the fact that the use of active participation has yet to be established, there is even the possibility that patient involvement in the guideline development process could hamper patient-centred care at the individual level. When the suggestion is raised that patient preferences have already been incorporated in the guidelines, the danger is that this could become a reason for the users of the guidelines not to pay as much attention to preferences at the individual level. A guideline based on active participation of all actors involved becomes a consensus document from which it 
could become difficult to deviate in individual cases. ${ }^{1}$ The methods used for participation, such as co-opting a patient representative into the group, are supposed to provide input regarding what 'the patient' with a particular disease or condition prefers and what 'the patient' experiences. Consequently, the uniqueness of every patient that is emphasised at physician-patient level is no longer reflected in the guidelines. Furthermore, since the contribution of patients to this process has yet to become clear the suggestion that patient preferences have already been incorporated in the guidelines is even further off the mark.

Attention in the guidelines for individual patient preferences can be accomplished by including a separate section or chapter on patient-physician communication the importance of which for patients was repeatedly stressed in the literature $[8,40]$. Recommendations can be given on how professionals could best organise this process. As we saw earlier, these issues are also raised by patients when they do contribute to the development process, implying that they already recognise its importance. Since it is not clear what becomes of these suggestions when they are raised by a patient in a group, we recommend attention be paid to this subject in all guidelines. A special patient version of the guidelines might further help individual patients in their decision-making process and should, therefore, be made available to patients who want to be actively involved in their own care. Research into patient preferences on these issues can still be used as input for the guidelines. For instance, surveys, or other types of research, could be done to determine the views of patients with a certain condition. If it is concluded that there is a paucity of such studies, as is sometimes done in the literature, it should be placed on the health research agenda.

Research into patient preferences can be used as evidence in the development process, but it should still be made clear that this research merely serves as a general overview of patient preferences and that it does not represent an individual patient's preferences. Professionals involved in the development process and who have the necessary skills to perform such literature searches, can be trusted to take these studies into account in their literature search. There is no compelling reason why patient representatives should be trained to perform this task.

\section{Other Reasons for Participation}

The above argument is relevant whenever the stated goal of active participation is to improve the quality of the guidelines. As we have seen, however, there are other arguments in the debate in favour of active participation. Legitimacy, in the sense that decisions are made in all openness with patients functioning as a kind of referee so the participants keep their eyes on the ball, can be seen as an important goal. Other arguments can also still apply. For instance, the normative argument that patients should participate in health care decision-making since they are the ones directly affected by it. Participation then becomes more of a goal in itself. One

\footnotetext{
1 Taking into account every possible argument in the development process other than medical evidence will make deviation from these guidelines ever more difficult. Other arguments that are already used are cost-efficiency, safety, usability, organisational feasibility and judicial considerations [53].
} 
could, of course, argue that democratic participation in guideline development is not a process that is primarily supposed to improve the quality of the guidelines. Democracy has many advantages. Nevertheless, ever since Plato, people interested in the quality of decisions have argued that improving the quality of decisions is not one of them. The democratic constitution of guidelines may be considered valuable for other reasons. For example, it may be good for people to participate in decisionmaking processes. De Tocqueville [13, p. 125] regarded the citizen jury as "one of the most effective means that the society can use for the education of the people". He saw jury duty not as something that would be beneficial for improving the quality of the judicial outcome, but as something that is good for educational purposes: "I do not know if the jury is useful to those who are parties to lawsuits, but I am certain that it is very useful to those who judge them." (ibid. p. 125). In this connection Gastil and Weiser [18] recently concluded that the jury promotes civic engagement; not only do they find that jury service spurs increased electoral participation, but it also broadens civic engagement such as an increased tendency to discuss public affairs and staying informed. These educational or empowerment purposes could also be an argument for asking patients to participate in decisionmaking processes. The group of people that is reached through the participation process would be quite small compared to the number of people involved in a citizen jury system. However, if patient participation in health care decision-making were viewed as part of a larger tendency to include citizens in decision-making processes, this would not be a problem. For some patients this empowerment could be especially important because their condition makes it difficult for them to work and participation in health care decision-making can provide an important means towards feeling useful again. Crawford et al. [12] concluded that patients' selfesteem improved as a result of their contributions. This could be considered a legitimate reason to continue participation processes. However, if civic education were the main reason to promote patient participation, certain participation methods should not be continued. At present, some patient representatives are paid staff members employed by a patient organisation, who have never experienced living with the condition themselves. The civic education goal would be lost on such participants.

Another principle based argument in favour of patient participation might be the balance of power or checks and balances. Patients are dependent on health care professionals, they are affected by their decisions, and hence one might argue that their presence in each and every organisation or forum involved in health care decision-making should be considered necessary as well as self-evident. Even if their involvement does not change the content of the guidelines much, it could make all parties in health care at least feel more like partners. When the principle based desirability is a position generally adhered to, it could be concluded that it is important to continue with active participation. However, then these arguments should also be the ones used in the discussion. This could prevent disappointment amongst participants who expect to have a great deal of influence on the content of the guidelines or who want to fully understand the whole process but cannot. Apart from this it would still be important to create room for individual patient preferences 
in the guidelines and not to present them as if thanks to the participation of patient representatives patient preferences have already been taken care off.

Open Access This article is distributed under the terms of the Creative Commons Attribution Noncommercial License which permits any noncommercial use, distribution, and reproduction in any medium, provided the original author(s) and source are credited.

\section{References}

1. AGREE Collaboration. (2001). Appraisal of Guidelines Research and Evaluation. AGREE Instrument, London.

2. Arnstein, S. R. (1969). A ladder of citizen participation. Journal of the American Planning Association, 39(4), 216-224. American Planning Association. doi:10.1080/01944366908977225.

3. Bastian, H. (1996). Raising the standard: Practice guidelines and consumer participation. International Journal for Quality in Health Care, 8(5), 485-490. doi:10.1093/intqhe/8.5.485.

4. Bauchner, H., \& Simpson, S. (1998). Specific issues related to developing, disseminating, and implementing pediatric practice guidelines for physicians, patients, family, and other stakeholders. Health Services Research, 33(4), 1161-1177.

5. Bensing, J. (2000). Bridging the gap. The separate worlds of evidence based medicine and patientcentered medicine. Patient Education and Counseling, 39, 17-25. doi:10.1016/S0738-3991(99) 00087-7.

6. Brainin, M., Barnes, M., Baron, J. C., Gilhus, N. E., \& Hughes, R. (2004). Guidance for the preparation of neurological management guidelines by EFNS scientific task forces-revised recommendations 2004. European Journal of Neurology, 11, 577-581. doi:10.1111/j.1468-1331. 2004.00867.x.

7. Burgers, J. S., Fervers, B., Haugh, M., Brouwers, M., \& Browman, G. (2004). International assessment of the quality of clinical practice guidelines in oncology using the appraisal of guidelines and research and evaluation instrument. Journal of Clinical Oncology, 22(10), 2000-2007. doi: 10.1200/JCO.2004.06.157.

8. Butow, P. N., Kazemi, J. N., Beeney, L. J., Griffin, A. M., \& Dunn, M. (1996). When the diagnosis is cancer: Patient communication experiences and preferences. Cancer, 77(12), 2630-2637. doi:10.1002/(SICI)1097-0142(19960615)77:12<2630::AID-CNCR29>3.0.CO;2-S.

9. Caron-Flinterman, J. F. (2005). A new voice in science: Patient participation in decision-making on biomedical research. Vrije Universiteit, Amsterdam.

10. Carter, A. O., Battista, R. N., Hodge, M. J., Lewis, S., \& Bansinski, A. (1995). Report on activities and attitudes of organizations active in the clinical practice guideline field. Canadian Medical Association Journal, 153(7), 901-907.

11. Cavelaars, E., Franx, G., Eland, A., \& Geelen, K. (2002). Cliëntenparticipatie bij richtlijnontwikkeling. Utrecht: Trimbos Instituut.

12. Crawford, M. J., Rutter, D., Manley, C., Weaver, T., \& Bhui, K. (2002). Systematic review of involving patients in the planning and development of health care. British Medical Journal, 325, 1263-1267. doi:10.1136/bmj.325.7375.1263.

13. De Tocqueville, A. (2000). Democracy in America. Indianapolis/Cambridge: Hackett Publishing Company Inc.

14. Duff, L. A., Kelson, M., Marriott, S., McIntosh, A., \& Brown, S. (1996). Clinical guidelines: Involving patients and users of services. Journal of Clinical Effectiveness, 1(3), 104-112.

15. Eccles, M., Clapp, Z., Grimshaw, J., Adams, P. C., Higgins, B., \& Purves, I. (1996). Developing valid guidelines: Methodological and procedural issues from the North of England evidence based guideline development project. Quality in Health Care, 5, 44-50.

16. Field, M. J., \& Lohr, K. N. (1992). Guidelines for clinical practice: From development to use. Washington DC: National Academy Press.

17. Gandjour, A., Westenhofer, J., With, A., Fuchs, C., \& Lauterbach, K. W. (2001). Development process of an evidence-based guideline for the treatment of obesity. International Journal for Quality in Health Care, 13(4), 325-332. doi:10.1093/intqhe/13.4.325. 
18. Gastil, J., \& Weiser, P. (2006). Jury service as an invitation to citizenship: Assessing the civic value of institutionalized deliberation. Policy Studies Journal: The Journal of the Policy Studies Organization, 34(4), 605-627. doi:10.1111/j.1541-0072.2006.00194.x.

19. Gezondheidsraad. (2000). Van implementeren naar leren; het belang van tweerichtingsverkeer tussen praktijk en wetenschap in de gezondheidszorg. Den Haag: Gezondheidsraad, publication nr. 2000/18.

20. Gilmore, A. (1993). Clinical practice guidelines: Weapons for patients, or shields for MDs? Canadian Medical Association Journal, 148(3), 429-431.

21. Goossensen, A., Van Der Veen, C., Van Der Linden, M., \& Franx, G. (2005). Perspectief op behandeling van mensen met een angststoornis: Inbreng van patiënten bij richtlijnontwikkeling. Tijdschrift voor Sociale Gezondheidszorg, 83(3), 166-171. TSG.

22. Graham, I. D., Beardall, S., Carter, A. O., Tetroe, J., \& Davies, B. (2003). The state of the science and art of practice guidelines development, dissemination and evaluation in Canada. Journal of Evaluation in Clinical Practice, 9(2), 195-202. doi:10.1046/j.1365-2753.2003.00385.x.

23. Grilli, R., Penna, A., Zola, P., \& Liberati, A. (1996). Physicians' view of practice guidelines: A survey of Italian Physicians. Social Science and Medicine, 43(8), 1283-1287. doi:10.1016/02779536(96)00040-8.

24. Grol, R. (2001). Improving the quality of medical care: Building bridges among professional pride, payer profit, and patient satisfaction. Journal of the American Medical Association, 286(20), 25782585. doi:10.1001/jama.286.20.2578.

25. Jarret, L., \& Patient Involvement Unit (PIU). (2004). A report on a study to evaluate patient/carer membership of the first NICE guideline development groups. National Institute for Clinical Excellence (NICE), National Health Service (NHS).

26. Kelson, M. (2001). Patient involvement in clinical guideline development-where are we now? The Journal of Clinical Governance, 9, 169-174.

27. Lanza, M. L. (2000). Consumer contributions in developing clinical practice guidelines. Journal of Nursing Care Quality, 14(2), 33-40.

28. Lui, K., Bajuk, B., Foster, K., \& Gaston, A. (2006). Perinatal care at the borderlines of viability: A consensus statement base don a NSW and ACT consensus workshop. The Medical Journal of Australia, 15(9), 495-500.

29. McInnes, E., Cullum, N., Nelson, E. A., Luker, K., \& Duff, L. A. (2000). The development of a national guideline on the management of leg ulcers. Journal of Clinical Nursing, 9, 208-217. doi: 10.1046/j.1365-2702.2000.00369.x.

30. Moreira, T. (2005). Diversity in clinical guidelines: The role of repertoires of evaluation. Social Science and Medicine, 60, 1975-1985. doi:10.1016/j.socscimed.2004.08.062.

31. Nease, R. F., \& Owens, D. K. (1994). A method for estimating the cost-effectiveness of incorporating patient preferences into practice guidelines. Medical Decision-Making, 14(4), 382-392. doi: 10.1177/0272989X9401400409.

32. Nilsen, E. S., Myrhaug, H. T., Johansen, M., Oliver, S., \& Oxman, A. D. (2006). Methods of consumer involvement in developing healthcare policy and research, clinical practice guidelines and patient information material (review), Cochrane Database of Systematic Reviews, Issue 3. Art. No.:CD004563.

33. Owens, D. K. (1998). Patient preferences and the development of practice guidelines. Spine Update, 23(9), 1073-1079.

34. Pagliari, C., \& Grimshaw, J. (2002). Impact of group structure and process of multidisciplinary evidence-based guideline development: An observational study. Journal of Evaluation in Clinical Practice, 8(2), 145-153. doi:10.1046/j.1365-2753.2002.00333.x.

35. Rankin, N., Newell, S., Sanson-Fisher, R., \& Girgis, A. (2000). Consumer participation in the development of psychosocial clinical practice guidelines: Opinions of women with breast cancer. European Journal of Cancer Care, 9, 97-104. doi:10.1046/j.1365-2354.2000.00198.x.

36. Rogers, W. A. (2002). Evidence-based medicine in practice: Limiting or facilitating patient choice? Health Expectations, 5, 95-103. doi:10.1046/j.1369-6513.2002.00168.x.

37. Salmon, P., \& Hall, G. M. (2003). Patient empowerment and control: A psychological discourse in the service of medicine. Social Science and Medicine, 57, 1969-1980. doi:10.1016/S02779536(03)00063-7.

38. Salmon, P., \& Hall, G. M. (2004). Patient empowerment or the emperor's new clothes. Journal of the Royal Society of Medicine, 97, 53-56. doi:10.1258/jrsm.97.2.53.

39. Saltman, D. C. (1998). Guidelines for every person. Journal of Evaluation in Clinical Practice, 4(1), 1-9. doi:10.1046/j.1365-2753.1998.t01-1-00001.x. 
40. Schofield, M. J., Walkom, S., \& Sanson-Fisher, R. (1997). Patient-provider agreement on guidelines for preparation for breast cancer treatment. Behavioral Medicine (Washington, DC), 23, 36-45.

41. Schunemann, H. J., Fretheim, A., \& Oxman, A. D. (2006). Improving the use of research evidence in guideline development: 10. Integrating values and consumer involvement. Health Research Policy and Systems, 4(22).

42. Schunemann, H. J., Hill, S. R., Kakad, M., Vist, G. E., Bellamy, R., et al. (2007). Transparent development of the WHO rapid advice guidelines. PLoS Medicine, 4(5), 0786-0793.

43. Sieders, R. (2006). Zwartboek cliëntenparticipatie bij de multidisciplinaire richtlijnen in de GGZ (Unpublished report).

44. Smallwood, R. A., \& Lapsley, H. M. (1997). Clinical practice guidelines: To what end? The Medical Journal of Australia, 166, 592-595.

45. Smolders, M., \& Braspenning, J. (2005). Depressie: behandel-en kwaliteitsdoelen. Centre for Quality of Care Research (WOK). St Radboud, Nijmegen: University Medical Centre.

46. Swinkels, A., Albarran, J. W., Means, R. I., Mitchell, T., \& Stewart, M. C. (2002). Evidence-based practice in health and social care: Where are we now? Journal of Interprofessional Care, 16(4), 335347. doi:10.1080/1356182021000008265.

47. Trappenburg, M. J. (2008). Genoeg is genoeg. Over gezondheidszorg en democratie. Amsterdam: Amsterdam University Press.

48. Tweede Kamer (parliamentary proceedings) (1995-1996). 24126(9).

49. Van Everdingen, J. J. E., Burgers, J. S., Assendelft, W. J. J., Swinkels, J. A., Van Barneveld, T. A., \& Van De Klunder, J. L. M. (2004). Evidence-based richtlijnontwikkeling: een leidraad voor de praktijk. Houten: Bohn Stafleu Van Loghum.

50. Van Veenendaal, H., Franx, G. C., Grol, M. H., Van Vuuren, J., Versluijs, M. M., \& Dekhuijzen, P. N. R. (2004). Patiëntenparticipatie in richtlijnontwikkeling. In J. J. E. Van Everdingen, et al. (Eds.), Evidence-based richtlijnontwikkeling. Een leidraad voor de praktijk. Houten: Bohn Stafleu Van Loghum.

51. Van Wersch, A., \& Eccles, M. (2001). Involvement in the development of evidence based clinical guidelines: Practical experiences from the North of England evidence based guideline development programme. Journal for Quality in Health Care, 10, 10-16. doi:10.1136/qhc.10.1.10.

52. Van Wersch, S. F. M., \& Van Den Akker, P. A. M. (2005). Cliëntenparticipatie bij multidisciplinaire richtlijnontwikkeling in de GGZ: Ervaringskennis is geen kennis!? IVA. Utrecht: Trimbos Instituut.

53. Wiersma, T. J., \& Burgers, J. S. (2004). Formuleren van aanbevelingen. In J. J. E. Van Everdingen, et al. (Eds.), Evidence-based richtlijnontwikkeling. Een leidraad voor de praktijk. Houten: Bohn Stafleu Van Loghum.

54. Williamson, C. (1998). The rise of doctor-patient workings groups. British Medical Journal, 317, 1374-1377.

55. Wright, J., Harrison, S., McGeorge, M., Patterson, C., Russel, D., et al. (2006). Improving the management and regerral of patients with transient ischaemic attacks: A change strategy for a health community. Quality \& Safety in Health Care, 15, 9-12. doi:10.1136/qshc.2005.014704.

56. www.cbo.nl.

57. www.trimbos.nl. 